\title{
Mineração
}

\section{Aplicação de emulsões na flotação do minério de zinco}

\author{
(Use of emulsions in zinc ore flotation)
}

\author{
Tiago Alvarenga Vitorino da Silva \\ Eng., Votorantim Metais, Mestrando do PPGEM/DEMIN/EM/UFOP.E-mail:tiagovitorino@vmetais.com.br \\ Marly Ávila de Carvalho \\ Graduanda de Engenharia de Minas.E-mail:marlyufop@yahoo.com \\ Marcel Guimarães Sigueira \\ Graduanda de Engenharia de Minas.E-mail: Marcel.ufop@yahoo.com.br \\ Thiago Nantes Teixeira \\ Eng., Votorantim Metais. E-mail: thiagoengminas@yahoo.com \\ Carlos Alberto Pereira \\ Dr., Professor Adjunto, PPGEM/DEMIN/EM/UFOP.E-mail:pereira@demin.ufop.br
}

\begin{abstract}
Resumo
Várias linhas de flotação de minérios oxidados de zinco já foram estudadas e, segundo a maioria dos pesquisadores, a flotação catiônica com altas concentrações de sulfeto de sódio, usando amina primária como coletor, tem sido a opção mais adequada para concentrar esses minérios. Nesse trabalho, investigou-se a aplicação de novos sistemas de reagentes para flotar o minério de zinco com willemita, em etapas de depressão de gangas, dispersão, sulfetização e flotação do zinco. Os testes de flotação, usando emulsão de amina com óleos vegetais e diesel, mostraram que a amina emulsificada apresentou um desempenho na flotação superior à amina não emulsificada, além de permitir uma redução significativa de sulfeto de sódio. Dos óleos vegetais estudados destacaram-se a mamona e o coco-babaçu, porém os resultados de recuperação foram inferiores ao óleo diesel.
\end{abstract}

Palavras-chave: Flotação, minério de zinco, emulsão.

\begin{abstract}
Several approaches to the flotation of oxidized zinc ores were already studied, and according to most of the researchers, the cationic flotation with high concentrations of sodium sulfide, using primary amine as collector, has been the most appropriate option to concentrate this type of ore. In this work, the application of innovative systems of reagents to float willemite was investigated, including the stages of gangue depression, dispersion, sulfidization and zinc flotation. The flotation tests using amine emulsion with vegetable oils and diesel oil showed that the amine emulsion yielded a better flotation performance than that of amine without emulsion, besides allowing a significant reduction of sodium sulfide dosage. Among the vegetable oils studied castor and babaçu coconut oils yielded reasonable results, despite not leading to the same zinc recovery levels achieved with diesel oil.
\end{abstract}

Keywords: Flotation, zinc ore, emulsion. 


\section{Introdução}

No passado, o minério de zinco da Votorantim Metais era concentrado através de etapas de britagem, classificação e deslamagem. Pelo fato da baixa quantidade de zinco, o processo teve que ser melhorado usando jigue, meio denso e um forno Waelz. O processo gravítico ainda deu baixas recuperações para esses tipos de minérios por causa da baixa seletividade. $\mathrm{O}$ alto custo operacional do forno Waelz tornou o processo inviável. Esses vários fatores levaram à necessidade de se desenvolverem novos processos, que fossem mais eficientes na concentração dos mesmos (Borges et alii, 1996).

Baltar e Villas Boas (1980) experimentaram quatro diferentes linhas de flotação para o minério oxidado de zinco de Vazante. Primeiramente, testou-se uma flotação de xantato com sulfetização prévia, fazendo-se testes com sulfato de cobre como ativador e aquecimento da polpa. Na segunda linha, flotaram a ganga com sulfonato de petróleo. Também analisaram a flotação inversa da dolomita com ácidos graxos e, na última linha, flotação catiônica precedida de sulfetização, onde foram obtidos os melhores resultados.

No presente trabalho, procurou-se verificar a aplicação de óleo diesel e óleos vegetais (mamona, babaçu, pinho, eucalipto, azeite de mamona e coco-babaçu) na flotação do minério de zinco de Vazante, buscando melhorar a recuperação desse minério.

\section{Materiais e métodos}

Primeiramente, foi feito o planejamento fatorial com as variáveis sulfeto de sódio, emulsão, silicato de sódio e hexametafosfato de sódio, visando a estabelecer as condições-padrão do desenvolvimento experimental do trabalho e depois se estudou a utilização de emulsões de amina com óleos diesel ou vegetais.

A Votorantim Metais foi responsável pela coleta das amostras e realização de análises químicas quantitativas e qua- litativas. As amostras foram provenientes da mina subterrânea de Vazante, passaram por etapas de britagem, peneiramento, homogeneização e moagem, sendo coletadas no "overflow" da ciclonagem do circuito de flotação de willemita. Para a realização dos ensaios de flotação, foi utilizado o laboratório do Departamento de Engenharia de Minas da Universidade Federal de Ouro Preto.

\subsection{Ensaios de flotação do minério de willemita}

Para os ensaios de flotação, foi utilizada a célula mecânica de flotação da CIMAQ INÚSTRIA S.A, modelo CFB-1000 do Departamento de Engenharia de Minas. Os ensaios realizados seguiram os seguintes procedimentos:

i. Amostra de 1000 g e $30 \%$ de sólidos em cuba de acrílico e agitação da polpa.

ii. Adição de depressor ( $\mathrm{CaO}$ e $\mathrm{MgO})$ e condicionamento por 2 minutos.

iii. Adição de dispersante e condicionamento por 2 minutos.

iv. Adição de sulfeto de sódio na concentração desejada, medição do pH e condicionamento por 3 minutos.

v. Adição de coletor ou emulsão e espumante e condicionamento por 2 minutos.

vi. Flotação por 2 minutos, obtendo os produtos afundado e flotado.

vii. Repetição da seqüência mais duas vezes, obtendo-se, finalmente, três concentrados.

Em todos os ensaios, a rotação da célula permaneceu em 1000rpm e a vazão de ar na flotação em 8L/min.

\section{Resultados e discussão}

\subsection{Estudo de emulsões}

Atualmente, a Votorantim Metais utiliza, para flotar o zinco, a partir do minério willemítico de Vazante, os reagen- tes sulfeto de sódio (ativador e modulador $\mathrm{pH}$ ), amina (coletor) e MIBIC (espumante). Nesse estudo testou-se o uso de amina emulsificada com óleo diesel, além da utilização dos óleos vegetais emulsificados com amina.

\subsection{Comparação dos coletores amina e emulsão}

Os resultados descritos a seguir mostram a utilização de uma emulsão de amina/óleo diesel/MIBC, na proporção de 1:0,16:0,4, além dos dispersantes silicato de sódio e hexametafosfato de sódio. Na Figura 1, pode-se notar a comparação entre amina e emulsão através dos testes Emulsão 1, Emulsão 2, Amina 1 e Amina 2, descritos na Tabela 1.

Os testes comparativos entre emulsão e amina permitiram as seguintes observações:

i. Os ensaios em que se utilizou a emulsão proporcionaram recuperações muito mais altas que os ensaios em que se utilizou amina, mesmo quando se aumentou a concentração de sulfeto de sódio (Amina 1).

ii. A combinação da emulsão com hexametafosfato de sódio (Emulsão 2) apresentou um teor de zinco no concentrado um pouco maior que a emulsão com silicato de sódio (Emulsão 1). Ambos os ensaios alcançaram recuperações praticamente iguais.

iii. Quando se testou uma baixa concentração de sulfeto de sódio para emulsão e amina (Emulsão 1 e 2 e Amina 2), notou-se que a recuperação caiu, significativamente, quando se utilizou amina como coletor, mostrando que o uso da emulsão permitiu flotar esse minério de zinco com uma menor concentração de sulfeto de sódio. Pereira (2004) estudou a flotação de minério com calamina e observou a possibilidade de flotar em valores de $\mathrm{pH}$ mais baixos, ou seja, menores concentrações de sulfeto de sódio, quando se utilizou uma emulsão de amina/ óleo diesel e MIBIC. Assim, não importa o valor de $\mathrm{pH}$ e, sim, a quantidade de sulfeto neces- 
Tiago Alvarenga Vitorino da Silva et al.

Tabela 1 - Descrição dos reagentes utilizados nos testes de flotação com os coletores amina e emulsão.

\begin{tabular}{c|c|c|c}
\hline Teste & Ativador & Coletor & Dispersante \\
\hline Emulsão 1 & Sulfeto de sódio, $500 \mathrm{~g} / \mathrm{t}$ & Emulsão, $500 \mathrm{~g} / \mathrm{t}$ & Silicato de sódio, $1000 \mathrm{~g} / \mathrm{t}$ \\
\hline Emulsão 2 & Sulfeto de sódio, $500 \mathrm{~g} / \mathrm{t}$ & Emulsão, $500 \mathrm{~g} / \mathrm{t}$ & Hexametafosfato, $1000 \mathrm{~g} / \mathrm{t}$ \\
\hline Amina 1 * & Sulfeto de sódio, $1878 \mathrm{~g} / \mathrm{t}$ & Amina, $120 \mathrm{~g} / \mathrm{t}$ & - \\
\hline Amina 2 & Sulfeto de sódio, $500 \mathrm{~g} / \mathrm{t}$ & Amina, $500 \mathrm{~g} / \mathrm{t}$ & Silicato de sódio, $1000 \mathrm{~g} / \mathrm{t}$ \\
\hline
\end{tabular}

* Condição representativa da operação atual Vazante.

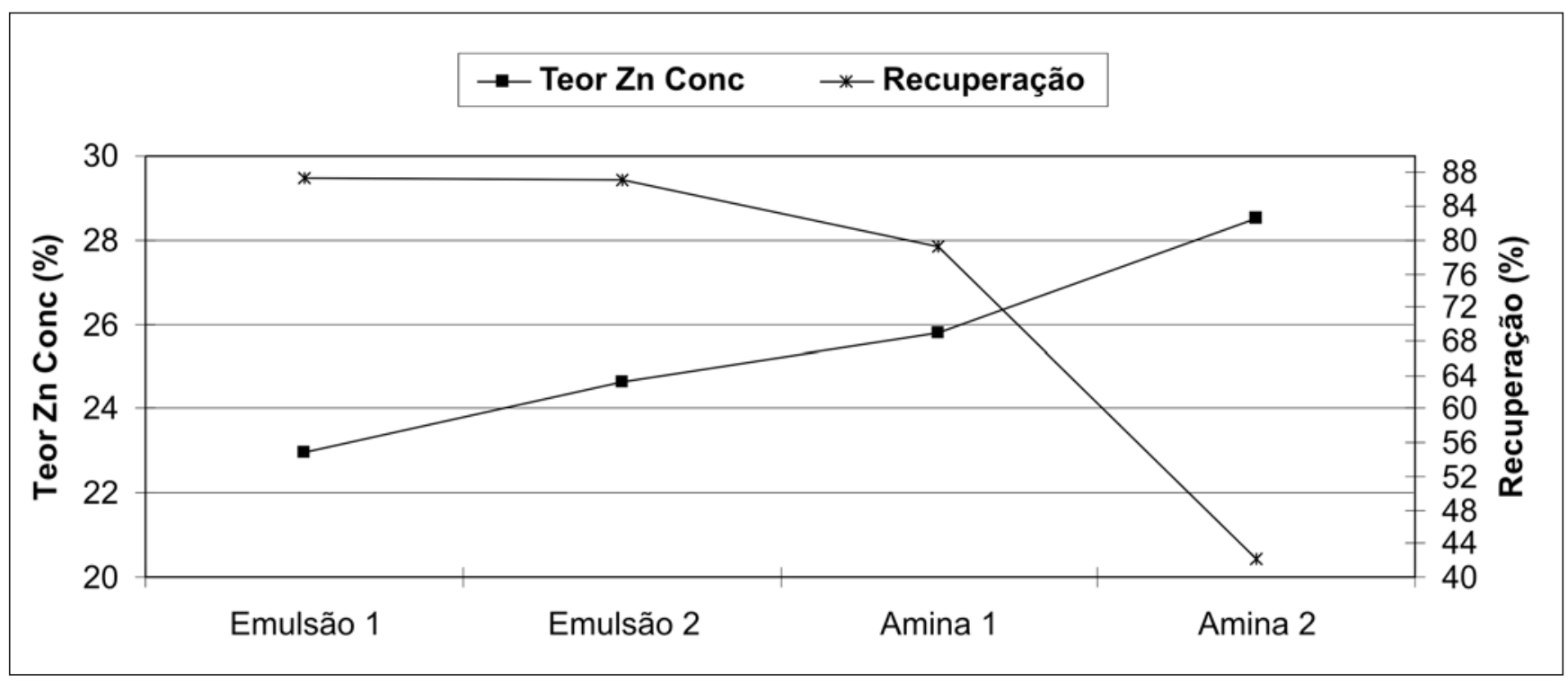

Figura 1 - Comparação entre amina emulsificada e amina não emulsificada.

sária para proporcionar a ativação da willemita entre os diversos minerais presentes.

iv. Pelos resultados descritos anteriormente verificou-se o significativo aumento de desempenho com a utilização de emulsão em comparação com a condição atual do processo em Vazante.

\subsection{Estudo de aminas emulsificadas com óleos vegetais}

A substituição do óleo diesel por um óleo vegetal na flotação proporcionará um menor impacto ao meio ambiente. Assim, nesse estudo, testou-se a emulsão de amina com óleos vegetais, comparando o desempenho desses óleos com a emulsão de amina com óleo diesel (Figura 2).
Entre os óleos vegetais testados, a mamona e o coco-babaçu foram os que mais se destacaram, apresentando recuperações de zinco em torno de 87\%. Apesar da recuperação de zinco na flotação ao se utilizar a emulsão de amina com mamona ou com coco-babaçu ter se aproximado da emulsão de amina com óleo diesel, os seus resultados de teor de zinco no concentrado foram, aproximadamente, inferiores em 2\%. Assim, a emulsão de amina com óleo diesel foi mais efetiva que a emulsão de amina com os óleos vegetais.

\section{Conclusões}

i. A amina emulsificada apresentou um bom desempenho na flotação do minério de zinco, mesmo quando se utilizou uma concentração de $500 \mathrm{~g} / \mathrm{t}$ de sulfeto de sódio, economizando grande quantidade de sulfeto de sódio e barrilha em relação ao praticado atualmente na usina.

ii. A interação da amina emulsificada com silicato de sódio ou com hexametafosfato aumentou, significativamente, a recuperação na flotação.

iii. A amina não emulsificada alcançou um baixo desempenho na flotação, quando se utilizou uma baixa concentração de sulfeto de sódio.

iv. Entre os óleos vegetais testados, a mamona e o coco-babaçu atingiram bons resultados na flotação, porém foram inferiores ao óleo diesel. 
Aplicação de emulsões na flotação do minério de zinco

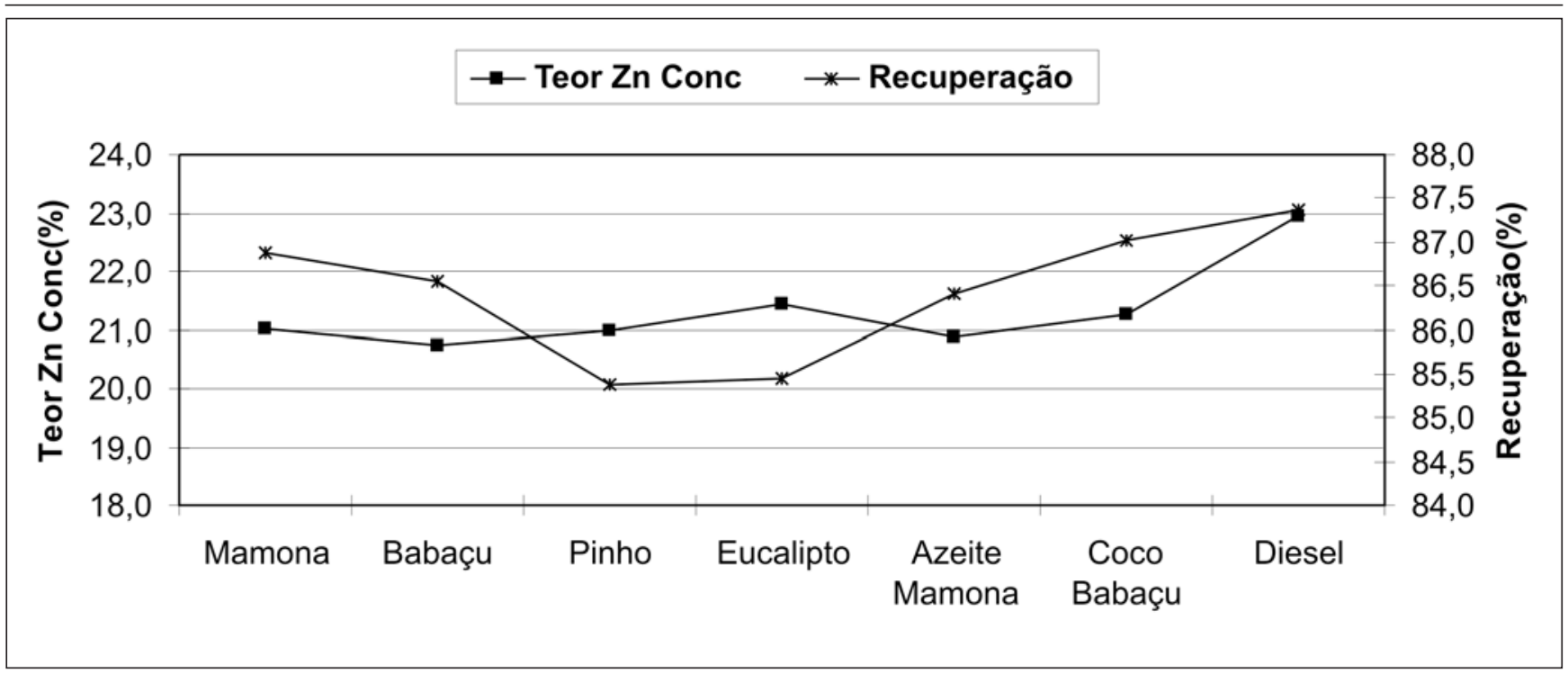

Figura 2 - Emulsão de amina com óleos vegetais e MIBC na proporção de 1:0,16:0,4.

\section{Referências Bibliográficas}

BALTAR, C. A. M., VILLAS BOAS, R. C. Flotação de minério oxidado de zinco de baixo teor. Série Tecnologia Mineral, Seção Beneficiamento, DNPM, 1980. 13p.

BORGES, A. A. M., MAFFEI, A. C., SILVA, M. E. M. C. Estudos visando à concentração de minérios oxidados de zinco willemíticos, de médio teor, através de flotação - escala-piloto. In: CONGRESSO ÍTALO-BRASILEIRO DE ENGENHARIA DE MINAS, 4. Canela-RS/ Brasil, 1996. p. 427-431.

PEREIRA, C. A. Estudo da dispersão e concentração da lama de minério oxidado de zinco. UFMG: 2004. 162p. (Tese de doutorado).

SALUM, M. J. G. Estudo da flotação dos minerais silicatados de zinco com amina em sistema sulfetizado. UFMG: 1982. 89p. (Dissertação de Mestrado).

SHIJIE, T. Flotation of oxidized and complex lead-zinc ores: research and practice, International Conference Mineral Processing and Extractive Metallurgy.In: JONES, M. J., GILL P. (Ed.). Yunnan Province, People’s Republic of Chine, October to November, 1984. p. 541-552.

Artigo recebido em 27/01/2007 e aprovado em 09/08/2007.

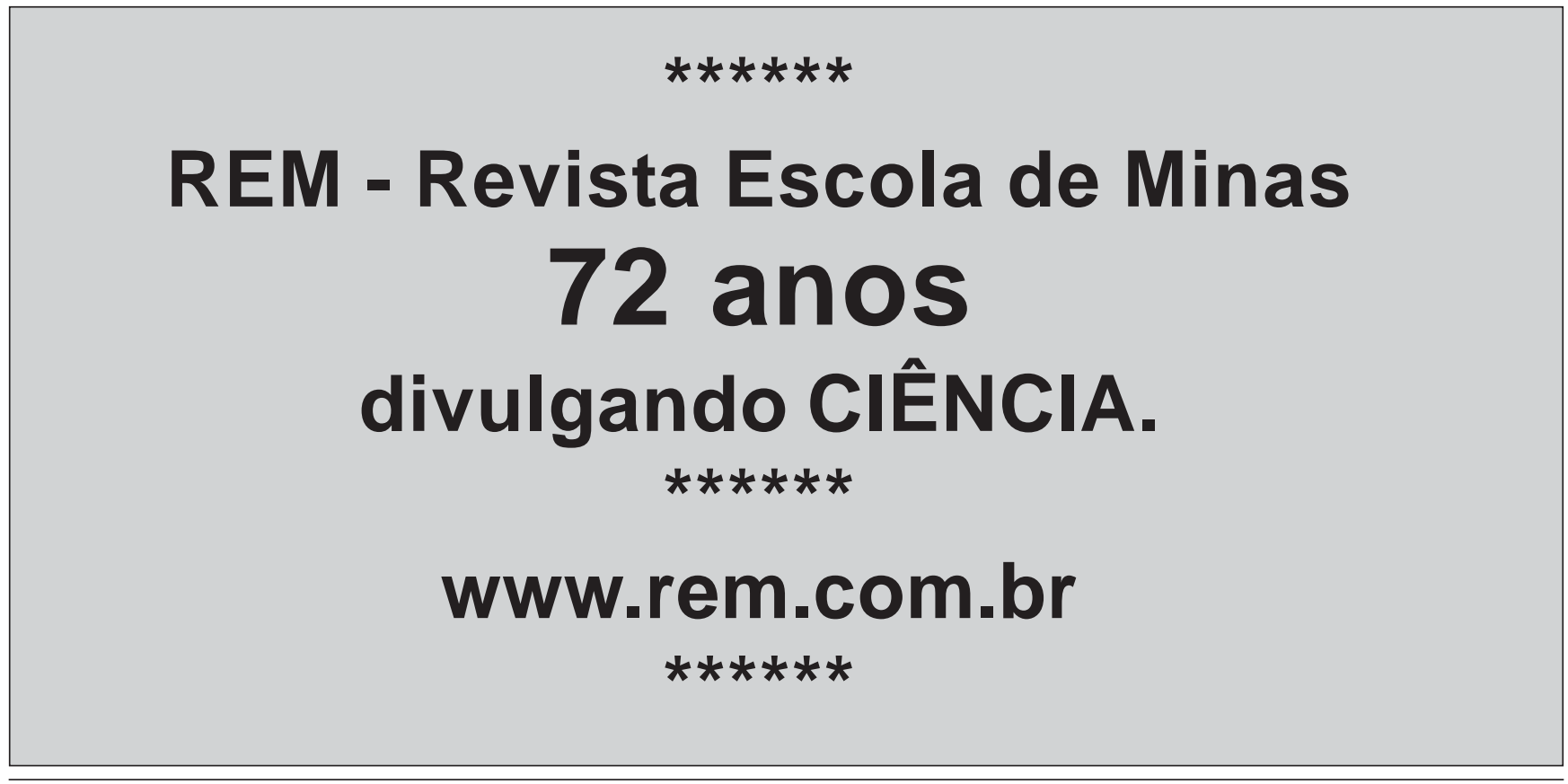

